\title{
Analysis of Translation of Audiovisual Humor in Iranian Series
}

\section{Mahmood Hashemian ${ }^{1}$ \& Maryam Farhang-Ju²}

\section{* Correspondence: \\ hashemian-m@sku.ac.ir \\ 1. Department of English Language, \\ Faculty of Letters \& Humanities, \\ Shahrekord University \\ 2. Shahid Chamran University of \\ Ahvaz}

Received: 30 October 2020

Revision: 11 January 2021

Accepted: 17 February 2021

Published online: 20 March 2021

\begin{abstract}
In recent years, audiovisual translation (AVT) has become omnipresent in different parts of the world; however, dubbing humor restrictions may hamper the translation in that maintaining the humor in the target language (TL) requires a high level of knowledge. Although several studies have attempted to describe the distribution of translation strategies, few systematic attempts are made to analyze the employed AVT strategies in humor series. The present study analyzed the Persian humor expressions' appropriacy and their translated versions in English through a qualitative study. To this aim, the dominant strategies used to render humor in the translated versions of 3 dubbed Iranian series (i.e., Shamsolemareh, Chimney, and Medical Building) were analyzed. Furthermore, the typologies of the employed audiovisual humor in the series were analyzed. Data analysis illustrated that clumsiness and parody were the most frequent humor typologies used in the series. The 3 strategies of omission, word-for-word translation, and free translation were the most frequent ones. In conclusion, the results indicated the failure to accommodate the Iranian series' humorous level, preventing the target audience from appreciating humor. Findings can contribute to the improvement of the quality of humor translation.
\end{abstract}

Keywords: Audiovisual translation (AVT), humor, Iranian series 


\section{Introduction}

Feature movies, television programs, theoretical plays, musical, opera, Web pages, and video games are just some examples of audiovisual products that require audiovisual translation (Antonini \& Chiaro, 2009). AVT is a language transferring technique that works as a tool for conveying ideas; it enables people of different ages, cultures, and languages to face new acts in different situations (Perego, 2012).

Dubbing and subtitling are the two most well-known methods for transferring language in translating mass audiovisual communication (Perego, 2012). Cintas (2009) describes subtitling as providing the translation of dialogue exchanges of the speaker in the written text format at the bottom of the screen. The other method, which is dominant, is dubbing. O'Connell (2003) believes that dubbing is a complex postproduction process and a rather long and complicated one. He defines it as a group activity involving several vital skills that may be combined and applied in various stages or sequences by a variable number of individuals. Therefore, subtitling and dubbing are different. Through subtitling, viewers can hear the dialogues, and at the same time, they can read the dialogue's translation.

However, watching movies with subtitles helps individuals improve their target language (TL) level; watching dubbed versions of movies is more convenient because they can hear dialogues in their first language (L1). Therefore, most individuals prefer dubbed movies and series (Perego, Del Missier, \& Stragà, 2018). To prepare dubbed movies and series, translators should find a proper replacement for the TL's soundtracks and dialogues (Martínez, 2004). Although translators must be faithful to the source language (SL) text (Martínez-Sierra, 2010), they should also be faithful to their society (Baker, 2006). Therefore, it is not easy to find the best equivalence to fulfill these duties and translate the SL text into TL so that the audience will understand it.

To make dubbed movies and series more comprehensible to TL audiences, the translators must consider cultural and social differences that exist between the two cultures (Pym, 2010). According to Keshavarz and Alimadadi Zonoozi (2011), translation is an ideological activity that can never be separated from its sociocultural context. The problem arises when the SL's culture is not compatible with the TL culture (Inggs \& Meintjes, 2009). Martínez-Sierra (2010) articulates that the main issue during translation refers to the dichotomy between form and content. Translation of cultural elements from one language into another is difficult for translators. Therefore, finding perfect equivalences in translating humor requires an in-depth knowledge of two languages and cultures (Wang, 2014).

Besides cultural differences, these difficulties may root in grammatical and lexical differences between SL and TL. Therefore, there is a significant gap between the two languages that translators should attempt to fill. Such a gap is more evident in translating humor texts because the word-for-word technique is impossible due to cultural differences (Antonini \& Chiaro, 2009). In recent years, a myriad of movies and series have been produced in Iran. With the advent of new technologies such as the Internet and satellites, the demand for AVT has increased and many companies are dubbing and subtitling movies every day. Therefore, there has been an increasing demand for dubbing and subtitling Iranian movies and series into English for those interested to watch Iranian movies and series.

Unlike previous research, the focus of this study was on translation of Persian into English. Therefore, we attempted to examine the probable problems in the translation of humor due to cultural differences. Besides, as Iranian translators are usually unidirectional and translate from English to Persian, we investigated the extent to which translators were successful in transferring humor and cultural elements to English speakers.

\subsection{Statement of the Problem}

The main aim of movie translation and dubbing it into TL is making films and film's dialogue more comprehensible to target audiences. Because the translators' role is to pursue this aim, they must consider cultural and social differences that exist between the two cultures. The theory of Skopos focuses on "the purpose of translation, which determines the translation methods and strategies that are to be employed in order to produce a functionally adequate result" (Munday 2001, p. 79). The theory of Skopos of TT is to entertain the target audience and make the dialogues more understandable to the viewers and listeners.

Among the mass media, comic programs are the best choice to make the audiences aware because while they make the audiences to laugh, they made them to think, too. Audience research on humor preferences suggests that understanding and appreciating different types of humor are highly dependent on cognitive and sociocognitive factors (Foot, 2017). People will laugh at subjects that are unexpected for them and make them surprise. According to the superiority theory, people laugh because they feel some kind of triumph over others or feel superior to them (Meyer, 
2000). Theories have been exploring to explain why we laugh at things and how they make us happy. From the perspective of the relief theory, people laugh because they need to reduce psychological tension from time to time (Meyer, 2000). The relief theory assumes that laughter and mirth result from the release of nervous. In this view, humor is mainly used as reveal suppressed desire in order to overcome sociocultural things in habitation.

Poem and humor are the two literary elements which are the cultural symbols of every society. Talaván and Costal (2017) claims that humor is one of the most difficult genres to be translated due to its connection to a specific culture, making the largest audience at times unaware of the original intention of laughter. During the process of translation, a translator should prepare himself or herself to face untranslatable culture-specific contents. Humor is a universal concept; it is widely used in many different forms of literature. The translation of humor is a stimulating challenge. Because cultures are different among languages, translators face some problems in their translations. According to Berger (1976, 1993), humor techniques fall into four general categories: language, logic, identity, and action. So, we tried to investigate the problems in translation of humor in comic series. Besides, because Iranian translators are usually unidirectional and translate from English to Persian, we investigated how much they are successful in transferring humor and cultural elements for English speakers.

\subsection{Research Questions}

Based on what was mentioned above, the following research questions were posed to be pursed in this study:

1. What strategies have been used in the English versions of three Iranian series: The case of Shamsolemareh, Chimney, and Medical Building?

2. Which translation strategies have been more frequently applied to render humor in the Persian series Shamsolemareh, Chimney, and Medical Building dubbed in English and how effective they are?

\section{Literature Review}

Among mass media, comic programs are the best choice for audiences aware of the present situation and society because they make the audience laugh and they made them think, as well. Humor has an undeniable, exteriorized manifestation; this manifestation may be laughter or smile (Vandaele, 2002). Raphaelson-West (1989) categorizes humor into three types of joke, satire, and parody. He divided jokes into three groups: linguistic, cultural, and universal. The typical example of a cultural joke is a pun. It is challenging to translate such jokes. Cultural jokes such as ethical jokes are more widely translatable. This scholar stated that "it is difficult to say whether there is such a thing as a universal joke" (p. 130). Satire is brutal to translate because it makes a mockery of things. Parody is also a mockery of a specific work and is among the most challenging humor typologies to translate.

Koestler (1993) considers verbal and situational humor. Verbal humor plays on sounds, words, and ideas and covers jokes, anecdotes, comic verse, bogus proverbs, nonsense verses, and satire. Situational humor, by contrast, involves such comic devices as imitation, impersonation (the most aggressive form being parody), and disguise, where the source of humor comes from the bisociation of man and machine, man-animal hybrid (like playful behavior in young animals and children), deformity, and the changing roles between the part and the whole.

As translators struggle to produce an optimal translation for humor, different methods are proposed to solve translation problems and help translators choose the best equivalence. These methods are called strategies or procedures in translation studies. Translation strategies are used when the literal translation is not appropriate (Martínez-Sierra, 2010). These strategies can fill the cultural gap among cultures. Davis (2003) presents a classification of translation strategies which consists of preservation, addition, omission, globalization, localization, transformation, and creation:

- Preservation: It involves the translation of the SL phrase directly into TL without the addition of any explanation.

- Addition: It is applied when the original text is ameliorated with additional information in the form of gloss, footnote, or introduction.

- Omission: It is applied when the message in SL is omitted in TL.

- Globalization: It is applied when SL's cultural terms are translated with more general, neutral expressions in TL.

- Localization: It is applied when SL's cultural terms are translated to a TL's formal equivalent. 
- Transformation: It is applied when SL is changed in TL to match with the TL culture reality.

- Creation: Translating cultural terms completely different in TL, which sometimes does not appear in SL.

To examine translation strategies, it is of great importance to know the reasons for translating a source text and the function of the target text (Munday, 2001). The main concern of translation strategies refers to literal and free translation, the first of which impairs the amount of comprehensibility. Some researchers (e.g., Jankowska, 2009; Martínez-Sierra, 2008, 2010) have investigated translation strategies from their points of view and different perspectives. Martínez-Sierra (2008), for instance, examined humor in the animated American television show (The Simpsons). His results indicated that (1) most humor is translatable, and (2) the role of translators as mediators are crucial because having shared background knowledge of existing assumptions is essential.

Jankowska (2009) examined the elements of humor in an American animated film (Shrek). His analyses indicated that the target text contained fewer instances of humorous elements than the source text, meaning that most of the humor was omitted in target translation. Besides, Balirano (2013) examined AVT of humor in the big bang theory, whose results indicated that translators failed to help the Italian audience understand and appreciate its subtle humor.

Khoshsaligheh, Ameri, and Mehdizadkhani (2018) analyzed the translation of taboos in English language films subtitled into Persian, whose results indicated that the taboo language translation strategies were classified into maintaining, deleting, mitigating, substituting, and amplifying. In another study, Afsari, Abootorabi, and Moeinzadeh (2018) examined the Friends series' Persian subtitles' most frequently applied strategies. The results showed that paronymy was the most frequently employed strategy (60\%), followed by homonymy (38.66\%) and homography (4\%). The results also indicated that the most frequent strategies used to translate the wordplays was replacing (78.66\%) and adapting strategies (12\%).

Khakshour Forutan and Modarresi (2018) analyzed the applied favorable translation by (non)professional translators. In so doing, End of Watch and Wolf of Wall Street were chosen. The chi-square results revealed there was a significant difference with respect to totally nine translation strategies for both series. Finally, Camilli (2019) examined the translated version (French) of the British comedy series A Touch of Cloth. Her results indicated that there was a high degree of faithfulness to the source text, which was due to the closeness of the English and French languages. The translators mostly employed the pun technique to translate the jokes.

\section{Methodology}

\subsection{Design of the Study}

The present study was a qualitative study whose aim was to describe how the humor language is translated into English in a corpus of English subtitles of Persian-speaking feature series which were translated and subtitled by IRIB.

\subsection{Instruments}

The humorous dialogues of the three Iranian series (i.e., Shamsolemareh, Chimney, and Medical Building) were the corpus for the present study. The original script of the mentioned series and their dubbed version were used in the present study. Shamsolemareh is an Iranian series directed by Saman Moghadam in 49 episodes in 2009. This series is produced in the form of satire. In the critics' points of view, Shamsolemareh can be a model for combining melodrama and sitcom, and they believe serious discussion such as marriage and modify consumption patterns are shown in the right way in this series.

The second series was Chimney, a humor series directed by Mohammad Hossein Latifi in 24 episodes in 2013. Chimney is classified in the humor genre. It is a family sitcom that has a special attention to family relationships and the effects of the family on society. The other vital aspect of this series is the combination of verbal humor and comic situation; most of the scenes are presented in comics.

The last series was Medical Building, directed by Soroush Sehat in 57 episodes in 2011. This series is produced in the satire form. We chose the Medical Building series because of two reasons: The first reason refers to humor elements, especially verbal humor, that included two layers, and the notable point refers to differences between the verbal and written versions of verbal humor. So, any verbal humor translation must rebuild the contrast that has created humor in SL. As mentioned above, verbal humor can be an inseparable part of this series. The second reason for choosing this series was the role of a low IQ secretary who always thinks she is right and the rest are wrong, and her instant on her correct performance created a satirical point in this series. 


\subsection{Procedure}

In this level, the following steps were taken to collect the required data:

1. The original version of the three series was collected from the Islamic Republic of Iran Broadcasting (IRIB), and the dubbed versions were prepared from English iFilm's Website.

2. The original and dubbed versions of series were carefully watched.

3. The vocabularies and expressions which carried unsuitable concept and were known as humor in Iran were selected.

4. The data were analyzed and five strategies were found.

5. At last, according to Buijzen and Valkenberg's (2004) theory which is based on humor typology, this study was investigated to see if humor comic elements are translatable or not.

\subsection{Data Collection}

In the first step, the researchers chose some popular TV series and watched them to find appropriate ones for the purpose of the study. We tried to include series of different genres, which included humor. After choosing the series, the original versions of the three series were collected from IRIB. The series and their translations are available online on iFilm Website. We referred to the Website to download and watch the series. The English versions of the series dubbed by iFilm translated by IRIB were collected, too.

\subsection{Data Analysis}

The employed translation strategies were classified using Davies' (2003) and Buijzen and Valkenberg's (2004) categorizations. First, Davies' (2003) categorization was used to categorize culture-specific translation strategies: (1) omission, (2) euphemism, (3) free translation, (4) word-for-word translation, and (5) localization.

- Localization: It is the freest form of translation and is used mainly for plays (comedies) and poetry; the themes, characters, plots are usually preserved, the SL culture is converted to the TL culture and the text is rewritten.

- Free translation: It produces the TL text without the style, form, or content of the original.

- Word-for-word translation: The SL word order is preserved and the words are translated singly by their most common meanings and out of context.

- Free translation: It attempts to render the exact contextual meaning of the original in such a way that both content and language are readily acceptable and comprehensible to the readership.

- Euphemism: It attempts to produce the positive meaning of the original within the constraints of the TL.

- Idiomatic translation: It reproduces the message of the original but tends to distort nuances of meanings by preferring colloquialisms and idioms where these do not exist in the original

Besides, Buijzen and Valkenberg (2004) categorize humor into 41 typologies. It is noteworthy to say that most elements of this typology were introduced by Berger (1976, 1993; see Table 1):

Table 1. Humor typology taken from Buijzen and Valkenberg (2004)

\begin{tabular}{ll}
\hline Humor Technique & \multicolumn{1}{c}{ Short Description } \\
\hline Absurdity & Nonsense, a situation that goes against all logical rules \\
\hline Anthropomorphism & Objects or animals with human features \\
\hline Bombast & $\begin{array}{l}\text { Talking in a high-flown, grandiloquent, or rhetorical } \\
\text { manner }\end{array}$ \\
\hline Chase & A pursuit or chase of someone or something \\
\hline
\end{tabular}




\begin{tabular}{|c|c|}
\hline Clownish Behavior & Making vigorous arm and leg movements \\
\hline Clumsiness & Lacking dexterity or grace \\
\hline Coincidence & A coincidental and unexpected occurrence \\
\hline Conceptual Surprise & $\begin{array}{l}\text { Misleading the audience by means of a sudden } \\
\text { unexpected change of concept }\end{array}$ \\
\hline Disappointment & A situation leading to (minor) disappointment \\
\hline Eccentricity & Someone deviating from the norms, an odd character \\
\hline Embarrassment & $\begin{array}{l}\text { An awkward situation in which someone gets a sense of } \\
\text { discomfort, uneasiness, or shame. }\end{array}$ \\
\hline Exaggeration & $\begin{array}{l}\text { Making an exaggeration or overstatement; reacting in an } \\
\text { exaggerated way, exaggerating the qualities of a person } \\
\text { or product }\end{array}$ \\
\hline Grotesque Appearance & $\begin{array}{l}\text { Someone who has a bizarre or monstrous appearance } \\
\text { with striking features. }\end{array}$ \\
\hline Ignorance & $\begin{array}{l}\text { Someone acting or behaving in a foolish, naive, gullible, } \\
\text { or childish humor }\end{array}$ \\
\hline Imitation & $\begin{array}{l}\text { Mimicking or copying someone's appearance or } \\
\text { movements while keeping one's own identity at the } \\
\text { same time }\end{array}$ \\
\hline Impersonation & $\begin{array}{l}\text { Taking on the identity of another person, intentionally } \\
\text { or unintentionally }\end{array}$ \\
\hline Infantilism & Playing with the sound of words \\
\hline Irony & $\begin{array}{l}\text { Saying one thing and meaning something else or exactly } \\
\text { the opposite of what you are saying }\end{array}$ \\
\hline Irreverent Behavior & $\begin{array}{l}\text { Lacking proper respect for authority or the prevailing } \\
\text { standards }\end{array}$ \\
\hline Malicious Pleasure & $\begin{array}{l}\text { Taking pleasure in other people's misfortune; victim } \\
\text { humor }\end{array}$ \\
\hline Misunderstanding & Misinterpreting a situation \\
\hline Outwitting & $\begin{array}{l}\text { Outsmarting someone or the establishment by retorting } \\
\text { responses and comeback }\end{array}$ \\
\hline Parody & Imitating a style or a genre of literature or other media \\
\hline Peculiar Face & Making a funny face, grimace \\
\hline Peculiar Music & Funny, an unusual music \\
\hline Peculiar Sound & Funny sound, unexpected sound, as in cartoons \\
\hline Peculiar Voice & Funny, unusual voice \\
\hline Pun & Playing with the meaning of words \\
\hline Repartee & Verbal banter, usually in a witty dialogue \\
\hline Repetition & Replay of the same situation \\
\hline
\end{tabular}




\begin{tabular}{|c|c|}
\hline Ridicule & Making a fool of someone, verbally or nonverbally \\
\hline Rigidity & $\begin{array}{l}\text { Someone thinking along straight lines; someone } \\
\text { conservative and flexible }\end{array}$ \\
\hline Sarcasm & $\begin{array}{l}\text { Biting remarks made with a hostile tone; sarcasm is } \\
\text { always a verbal put down. }\end{array}$ \\
\hline Satire & Making a fool of or poking fun at well-known things \\
\hline Scale & $\begin{array}{l}\text { Very large or small sizes of objects that surpass people's } \\
\text { logical expectation. }\end{array}$ \\
\hline Sexual Allusion & $\begin{array}{l}\text { Making a reference or insinuation to sexual or naughty } \\
\text { matter }\end{array}$ \\
\hline Slapstick & $\begin{array}{l}\text { Physical pie-in-the-face humor, often involving } \\
\text { degradation of someone's status }\end{array}$ \\
\hline Speed & Talking or moving in very fast or slow motion \\
\hline Stereotype & $\begin{array}{l}\text { Stereotyped or generalized way of depicting members of } \\
\text { a certain nation, gender, or other groups }\end{array}$ \\
\hline Transformation & $\begin{array}{l}\text { Someone or something on another form or someone or } \\
\text { something undergoing a metamorphosis, before/after }\end{array}$ \\
\hline Visual Surprise & A sudden, unexpected visual/physical change \\
\hline
\end{tabular}

In this study, we used the abovementioned typology because it covers humor concepts in detail. The data were, then, analyzed to find the frequently employed humor strategies and translation strategies of humor in the movies' original and dubbed versions.

\section{Results}

After analyzing the original and dubbed versions of the movies, five strategies were observed in the rendering of the humor expressions of Shamsolemareh, Chimney, and Medical Building: (1) omission, (2) euphemism, (3) free translation, (4) word-for-word translation, and (5) localization. The word-for-word translation was the first and most frequently used translation strategy $(34.13 \%)$ found in the corpus. As for word-for-word translation, the SL word order was preserved and the words were translated singly by their most common meanings, out of context. In word-forword translations, the translator acts as a machine: The translator renders the text from one language into another without conveying the sense of the original, whereas through this type of translation, speech or word changes by one word at the same time. The translator does not have any attention to TL.

Table 2. Examples for portraying use of word-for-word strategy in dubbing

\begin{tabular}{|c|c|}
\hline Source Language & Rendition in TL \\
\hline مضايقه نكن انقولتم نيار & Don't do anything, don't leave me some excuse. \\
\hline ديكه دارى مغلته ميكنى & You are in argument with me. \\
\hline تكيه بر جاى بزركان نتو ان زد به كز اف! & $\begin{array}{l}\text { Is like they say; you should not sit because it does not belong to } \\
\text { you. }\end{array}$ \\
\hline
\end{tabular}

The second most frequent strategy $(32.24 \%)$ was free translation. Free translation refers to L text production without the original's style, form, or content. In this strategy, the translator's aim is just rendering the meanings of terms in SL style (see Table 3). 
Table 3. Examples for portraying use of free translation strategy in dubbing

\begin{tabular}{ll}
\hline Source Language & Rendition in TL \\
\hline ديخه دارى مغلته ميكنى & You are in argument with me. \\
\hline شيرين بفرمايين & Please have some sweet. \\
\hline حرفهاى صدنا يه غاز & She starts nonstop talking nonsense. \\
\hline
\end{tabular}

The third dominant strategy was omission $(21.37 \%)$, concerned mainly with replacing the source text with nothing and was frequently used by the translators of the Iranian series (see Table 4).

Table 4. Examples for portraying use of omission strategy in dubbing

\begin{tabular}{ll}
\hline Source Language & Rendition in TL \\
\hline خيلى رفتار ناشايستيه & Omission \\
\hline كُاب بهن روتون آقا نمك كير نميشى & Omission \\
\hline
\end{tabular}

The next frequent strategy was euphemism (7.4\%), which refers to substituting a suitable and pleasant term to replace an offensive term. The translator rendered some examples so that the negative connotation of the terms was turned into inoffensive terms (see Table 5).

Table 5. Examples for portraying use of euphemism strategy in dubbing

\begin{tabular}{|c|c|}
\hline Source Language & Rendition in TL \\
\hline غلط كردم & I'm really sorry! \\
\hline تَمَركيدى & You are sitting here. \\
\hline 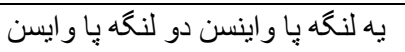 & They are waiting for him. \\
\hline
\end{tabular}

With the lowest percentage $(4.3 \%)$, localization is applied when cultural terms in SL are translated to a formal equivalent in TL, which was another strategy used by the translators (see Table 6).

Table 6. Examples for portraying use of localization strategy in dubbing

\begin{tabular}{|c|c|}
\hline Source Language & Rendition in TL \\
\hline من هميشّه زوج و فرد رو با هم قاطى ميكنم & I always mix remarkable and markable with each other. \\
\hline جشمم به كف يُش & Thanks God for thousand, Thanks God, Thanks! \\
\hline ببين تو كفششون ريكى جانمونده باشه & They don't have any tricks on their sleeves. \\
\hline
\end{tabular}

Table 7 indicates the frequency and percentage of occurring of the employed strategies in the dubbed versions of the series: 
Table 7. Frequencies and percentages of five translation strategies employed in the three series

\begin{tabular}{|c|c|c|c|c|c|c|}
\hline Strategies & & Localization & Euphemism & Omission & $\begin{array}{c}\text { Free } \\
\text { Translation }\end{array}$ & $\begin{array}{l}\text { Word -for- } \\
\text { Word }\end{array}$ \\
\hline \multicolumn{7}{|l|}{ Series } \\
\hline \multirow[t]{2}{*}{ Medical Building } & $\mathrm{F}$ & 1 & 0 & 13 & 5 & 13 \\
\hline & $\mathrm{P}$ & $3.1 \%$ & $0 \%$ & $40 \%$ & $15.6 \%$ & $40 \%$ \\
\hline \multirow[t]{2}{*}{ Shamsolemareh } & $\mathrm{F}$ & 1 & 0 & 3 & 11 & 8 \\
\hline & $\mathrm{P}$ & $4.3 \%$ & $0 \%$ & $13 \%$ & $47.8 \%$ & $34.7 \%$ \\
\hline \multirow[t]{2}{*}{ Chimney } & $\mathrm{F}$ & 1 & 4 & 2 & 6 & 5 \\
\hline & $\mathrm{P}$ & $5.5 \%$ & $22.2 \%$ & $11.1 \%$ & $33.3 \%$ & $27.7 \%$ \\
\hline \multirow[t]{2}{*}{ Total } & $\mathrm{F}$ & 3 & 4 & 18 & 22 & 26 \\
\hline & $\mathrm{P}$ & $4.3 \%$ & $7.4 \%$ & $21.37 \%$ & $32.24 \%$ & $34.13 \%$ \\
\hline
\end{tabular}

In the subsequent section, the results obtained from watching the series and extracting the humor terms are reported.

Table 8. Frequencies and percentages of five translation strategies employed in the three series

\begin{tabular}{|c|c|c|c|c|c|}
\hline Humor Typology & & Medical Building & Shamsolemareh & Chimney & Total \\
\hline \multirow[t]{2}{*}{ Clumsiness } & $\mathrm{F}$ & 16 & 2 & 0 & 18 \\
\hline & $\mathrm{P}$ & $51.6 \%$ & $6.8 \%$ & $0 \%$ & $19.46 \%$ \\
\hline \multirow[t]{2}{*}{ Parody } & $\mathrm{F}$ & 2 & 10 & 5 & 17 \\
\hline & $\mathrm{P}$ & $6.4 \%$ & $34.4 \%$ & $41.6 \%$ & $27.46 \%$ \\
\hline \multirow[t]{2}{*}{ Sarcasm } & $\mathrm{F}$ & 0 & 2 & 2 & 4 \\
\hline & $\mathrm{P}$ & $0 \%$ & $6.8 \%$ & 16.6 & $7.8 \%$ \\
\hline \multirow[t]{2}{*}{ Peculiar sound } & $\mathrm{F}$ & 1 & 1 & 0 & 2 \\
\hline & $\mathrm{P}$ & $3.2 \%$ & $3.4 \%$ & $0 \%$ & $2.2 \%$ \\
\hline \multirow[t]{3}{*}{ Peculiar Voice } & $\mathrm{F}$ & 3 & 7 & 0 & 10 \\
\hline & $\mathrm{P}$ & $9.6 \%$ & $24.1 \%$ & $0 \%$ & $11.23 \%$ \\
\hline & $\mathrm{F}$ & 0 & 2 & 1 & 3 \\
\hline Peculiar Face & $\mathrm{P}$ & $0 \%$ & $6.8 \%$ & $8.3 \%$ & 5.03 \\
\hline \multirow[t]{2}{*}{ Pun } & $\mathrm{F}$ & 0 & 2 & 0 & 2 \\
\hline & $\mathrm{P}$ & $0 \%$ & $6.8 \%$ & $0 \%$ & $2.2 \%$ \\
\hline \multirow[t]{2}{*}{ Scale } & $\mathrm{F}$ & 0 & 2 & 0 & 2 \\
\hline & $\mathrm{P}$ & $0 \%$ & $6.8 \%$ & $0 \%$ & $2.2 \%$ \\
\hline \multirow[t]{2}{*}{ Infantilism } & $\mathrm{F}$ & 5 & 0 & 0 & 16 \\
\hline & $\mathrm{P}$ & $16.1 \%$ & $0 \%$ & $0 \%$ & $5.36 \%$ \\
\hline
\end{tabular}




\begin{tabular}{llllll}
\hline Absurdity & $\mathrm{F}$ & 1 & 0 & 0 & 1 \\
\multirow{3}{*}{ Misunderstanding } & $\mathrm{P}$ & $3.2 \%$ & $0 \%$ & $0 \%$ & 1.06 \\
\multirow{3}{*}{ Speed } & $\mathrm{F}$ & 0 & 1 & 0 & 1 \\
& $\mathrm{P}$ & $0 \%$ & $3.4 \%$ & $0 \%$ & 1.06 \\
Bombast & $\mathrm{F}$ & 2 & 0 & 0 & 2 \\
& $\mathrm{P}$ & $6.4 \%$ & $0 \%$ & $0 \%$ & $2.2 \%$ \\
Irrelevant Behavior & $\mathrm{F}$ & 0 & 0 & 5 & 5 \\
& $\mathrm{P}$ & $0 \%$ & $0 \%$ & $41.6 \%$ & $1.66 \%$ \\
& $\mathrm{~F}$ & 1 & 0 & 0 & 1 \\
& $\mathrm{P}$ & $3.2 \%$ & $0 \%$ & $0 \%$ & 1.06 \\
\hline
\end{tabular}

The most employed humor typology was parody $(27.46 \%$ ). Clumsiness with $27.46 \%$ was the second mostly used humor typology that was applied by the comedian.

\section{Discussion}

In this study, humor strategies were analyzed and categorized based on Buijzen and Walkenberg's (2004) humor typology. To answer the first and second questions, the employed translation strategies were analyzed. The results indicated that parody had been used in several parts of Shamsolemareh series. Among all the 41 humor typologies (see Table 1), the comedian just used only 14 typologies to make the situation fun. Among all the 14 typologies, clumsiness with $24.6 \%$ was the mostly used humor typology applied by the comedian and, because of the ways of making humor in this typology, the translator respectively used word-for-word and free translations. For parody and verbal humor typology (peculiar voice and peculiar sound) with $23.2 \%$, the translator used omission and word-forword translation. In parody, the comedian makes the comedy situation using proverbs and poems that are retrieved from that specific culture. In this condition, the translator must do his or her best to make them comprehensible for foreign audiences and, at the same time, make them laugh.

For clumsiness, as the second mostly used humor typology, the translators used word-for-word and free translation due to this humor typology's nature. In fact, humor is shown with the words; therefore, the translator's elbowroom is broader than situations that must translate verbal humor or parody related to their ways of expression. Among all humor and cultural terms of the series, $90 \%$ were related to omission, free translation, and word-for-word in which the Iranian translators had introduced in the rendition localization strategy with $4.1 \%$ is the only strategy which shows that the translator did not apply any change in the process of translation and just expressed the humor terms as they were in the original versions.

The results are in line with previous research (e.g., Jankowska, 2009). Davies (2003) explains that one of the strategies most translators employ is omission in AVT, especially when a text is hardly translatable. In the case of cultural references, sometimes it is more probable to "omit a problematic culture-specific item altogether so that no trace of it is found in the translation" (p.79). To discuss the reason for manipulation in the translations, we classified all the humorous that were obtained based on three series in three groups: violence, proverbs, and cultural terms. These three groups are based on the community relations known as cultural values and definitions of humor in the Iranian society.

The first group is related to violence. In all the three series, no sign of violence was found; however, there was a sign of endeavor in Chimney's main character that he had a kind of violence in his speech. Chimney portrayed people's real life and showed comic and serious scenes altogether. In this situation, we do not mean sheer violence. It refers to the main character's violence that makes a special kind of comedy. The translator translated his dialogue in a wordfor-word way and was not successful in tone rendition, whereas his tone made humor situations.

The second group refers to proverbs. Both proverbs and poems are captured from all cultures and they demand their unique way of translation. Among all the three series studied in this research, proverbs were used in Shamsolemareh. The writer of Shamsolemareh used proverbs in a new way and made humor conditions with them. Proverbs were used 
by an uneducated woman who did not use them in the right opportunity and did not know anything about their meanings. In this situation, the translator used word-for-word translation. So, the way he used to translate caused some problems. Challenges always accompanied translated proverbs and they were stated in the wrong way in this series. The translator used a word-for-word strategy in his translation. So, the translator was unable to make a common situation for both SL and TL audiences.

And, the third group refers to cultural elements and humor is the language of societies. Humor is a way to speak about society's problems. Medical Building's writers were focused on the cultural elements of the community. The translator applied word-for-word and free translation to render the cultural elements among the cultures. For example, Kasra is an Iranian name that the Persian language speakers do not pronounce Kasra as how they spell it. Medical Building's writers focused on this point, which is omitted by the translator. The results can be explained by those of scholars (e.g., Antonini, 2007; Martínez-Sierra, 2014) in that a set of cultural-bound references hinder the successful translation of humor on screen. The same dialogue lines are frequently seen in this series and the translator omits all of them. This study shows that when the Iranian audiences watch the dubbed version of Medical Building, they do not get the impression as a sitcom must make for them.

\section{Conclusion}

AVT is one of the essential tools that can transfer a society's culture to another and it becomes more accessible by dubbing. Increasing the numbers of series and humor film's situation in the world and their popularity among peoples have caused the Iranian translators to decide to dub them for foreign audiences. Humor is the literary element that is the cultural symbol of every society. Therefore, we aimed to investigate the translations of humor terms in the series and examine the applied strategies. The observation of the translational strategies and general trends employed in the three series taken into consideration indicate incompetency in the rendering of humor, which is often omitted strategies. There are always certain limitations that may act as an obstacle to the process of research: First, we did not have access to the translators of the series directly. Future research can focus on translators' roles and other factors that may affect the translation process (e.g., age and gender). Therefore, we had to refer to iFilm channel to access the dubbed series. Second, there was only one dubbed version of each series. Comparing different translations of a series can provide further insights into the issue.

\section{Implications}

The results of current study provide some insights into the applied translation strategies of humor. Using the findings, translators can check their weaknesses and rectify them. The findings of this study revealed a significant weakness of the translators in resorting to the omission/addition strategy which reflects a lack of linguistic competence, which needs to be addressed by translation instructors and those who control translation quality. Long-term application of this strategy would end up in low-quality translations and translators, rather than pushing translators to improve the quality of their translations and no reaction to this trend can, substantially, affect the quality of translations into the Persian language.

\section{References}

Afsari, S., Abootorabi, E., \& Moeinzadeh, S. N. (2018). An analysis of audiovisual subtitling translation focusing on wordplays from English into Persian in the Friends TV series. Journal of Language and Translation, 8(2), 1-10. http://ttlt.azad.ac.ir/article_543418.html

Antonini, R. (2007). SAT, BLT, spirit biscuits, and the third amendment: What Italians make of cultural references in dubbed texts. In Y. Gambier, M. Shlesinger, \& R. Stolze (Eds.), Doubts and directions in translation studies (pp. 153-167). Amsterdam, Netherlands: John Benjamins. https://doi.org/10.1075/btl.72.17ant

Antonini, R., \& Chiaro, D. (2009). The perception of dubbing by Italian audiences. In Audiovisual translation (pp. 97-114). London: Palgrave Macmillan. https://doi: 10.1057/9780230234581_8

Baker, M. (2006). Translation a narrative account and conflict. London: Routledge. https://doi: $10.4324 / 9780203099919$

Balirano, G. (2013). The strange case of the big bang theory and its extraordinary Italian audiovisual translation: a multimodal corpus-based $\quad$ analysis. $\quad$ Perspectives, $\quad$ 21(4), https://doi.org/10.1080/0907676X.2013.831922 
Berger, A. A. (1976). Laughing matter: A symposium: Anatomy of the joke. Journal of Communication, 26(3), 113115. https://doi.org/10.1111/j.1460-2466.1976.tb01913.x

Berger, A. A. (1993). An anatomy of humor. New Brunswick, NJ: Transaction Publishers.

Buijzen, M., \& Valkenberg, P. M. (2004). Developing typology of humor in audiovisual media. Media Psychology, 6(2), 147-167. doi: 10.1207/s1532785xmep0602_2

Camilli, L. P. (2019). A case study of the audiovisual translation of wordplay. Journal of Audiovisual Translation, 2(1), 75-103. https://doi.org /10.47476/jat.v2i1.24

Cintas, J. D. (2009). New trends in audiovisual translation. London: Cromwell Press Group Ltd. https://doi.org/10.21832/9781847691552

Davis, E. E. (2003). A golbin or a dirty nose? The Translator, 9(1), 65-100. https://doi.org/10.1080/13556509.2003.10799146

Foot, H. (2017). Humor and laughter: Theory, research, and applications. New York: Routledge.

Inggs, J., \& Meintjes, L. (2009). Translation studies in Africa. Bloomsbury Publishing. https://www.bloomsbury.com/us/translation-studies-in-africa-9781847061775/

Jankowska, A. (2009). Translating humor in dubbing and subtitling. Translation Journal, 13(2), 134-148. https://translationjournal.net/journal/48humor.htm

Khakshour Forutan, M., \& Modarresi, G. (2018). Translation of cultural taboos in Hollywood movies in professional dubbing and nonprofessional subtitling. Journal of Intercultural Communication Research, 47(6), 454-473. https://doi.org/10.1080/17475759.2018.1480516

Keshavarz, M. H., \& Alimadadi Zonoozi, L. (2011). Manipulation of ideology in translation of political texts: A critical discourse analysis perspective. Journal of Language and Translation, 2(1), 1-12. http://ttlt.azad.ac.ir/article_529069.html

Khoshsaligheh, M., Ameri, S., \& Mehdizadkhani, M. (2018). A sociocultural study of taboo rendition in Persian fansubbing: An issue of resistance. Language and Intercultural Communication, 18(6), 663-680. https://doi.org/10.1080/14708477.2017.1377211

Koestler, A. (1993). Humor and wit. In R. McHenry (Ed.), Encyclopedia Britannica (pp. 684-685). Chicago: Encyclopedia Britannica, Inc.

Martínez, X. (2004). Film dubbing, its process, and translation. In P. Orero (Ed), Topics in audiovisual translation (pp. 3-9). Amsterdam: John Benjamins Publishing Company. https://doi.org/10.1075/btl.56.03mar

Martínez-Sierra, J. J. (2008). Humor y traducción. Los Simpson cruzan la frontera. The Journal of Specialized Translation, 11, 252-271.

Martínez-Sierra, J. J. (2010). Building bridges between cultural studies and translation studies: With reference to the audiovisual field. Journal of Universal Language, 11(1), 115-136. doi: 10.22425/jul.2010.11.1.115

Martínez-Sierra, J. J. (2014). Dubbing or subtitling humor: Does it really make any difference? In L. de Rosa et al. (Eds.), Translating humor in audiovisual texts (pp. 311-332). Oxford: Peter Lang. https://doi.org/10.3726/978-3-0351-0740-1

Meyer, J. C. (2000). Humor as a double-edged sword: Four functions of humor in communication. Communication Theory, 10(3), 310-331. https://doi.org/10.1111/j.1468-2885.2000.tb00194.x

Munday, J. (2001). Introducing translation studies. Theories and applications. London, New York: Routledge.

O'Connell, E. (2000). The role of screen translation: A response. Current Issues in Language \& Society, 7(2), 169174. https://doi.org/10.1080/13520520009615578

Perego, E. (2012). Eye tracking in audiovisual translation. Rome: Aracne. 
Perego, E., Del Missier, F., \& Stragà, M. (2018). Dubbing vs. subtitling: Complexity matters. Target: International Journal of Translation Studies, 30(1), 137-157. https://doi.org/10.1075/target.16083.per

Pym, A. (2010). Exploring translation theories. London and New York: Routledge.

Raphaelson-West, D. (1989). On the feasibility and strategies of translating humor. Meta: Translators' Journal, 34(1), 128-141. https://doi.org/10.7202/003913ar

Talaván, N., \& Costal, T. (2017). IDub-The potential of intralingual dubbing in foreign language learning: How to assess the task. Language Value, 9(1), 62-88. doi: 10.6035/LanguageV.2017.9.4

Vandaele, J. (2002). Introduction: (re) constructing humor: meanings and means. The Translator, 8(2), 149-172. https://biblio.ugent.be/publication/8564080

Wang, F. (2014). An approach to domestication and foreignization from the angle of cultural factors translation. Theory and Practice in Language Studies, 4(11), 2423-2427. https://doi.org/10.4304/tpls.4.11.2423-2427 